\title{
Os gêneros Calycorectes O. Berg, Hexachlamys O. Berg, Myrcianthes O. Berg, Myrciaria O. Berg e Plinia L. (Myrtaceae) na planície alagável do alto rio Paraná, Brasil ${ }^{1}$
}

\author{
Mariza Barion Romagnolo ${ }^{2,4}$ e Maria Conceição de Souza ${ }^{3}$
}

Recebido em 13/08/2003. Aceito em 11/02/2004

\begin{abstract}
RESUMO - (Os gêneros Calycorectes O. Berg, Hexachlamys O. Berg, Myrcianthes O. Berg, Myrciaria O. Berg e Plinia L. (Myrtaceae) na planície alagável do alto rio Paraná, Brasil). O presente estudo teve por objetivo o levantamento das espécies de Calycorectes O. Berg, Hexachlamys O. Berg, Myrcianthes O. Berg, Myrciaria O. Berg e Plinia L. para a planície alagável do alto rio Paraná, localizada nos

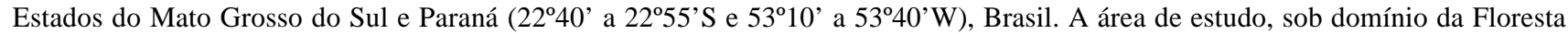
Estacional Semidecidual Submontana, compreende formações ripárias do rio Paraná, de suas ilhas e tributários. As espécies registradas foram Calycorectes psidiiflorus (O. Berg) Sobral, Hexachlamys edulis (O. Berg) Kausel \& D. Legrand, Myrcianthes pungens (O. Berg) D. Legrand, Myrciaria delicatula (DC.) O. Berg, M. cuspidata O. Berg, Plinia rivularis (Cambess.) Rotman e P. trunciflora (O. Berg) Kausel. Os meses que reuniram maior número de espécies em floração e frutificação foram, respectivamente, setembro e novembro de 2000 e 2001. Calycorectes psidiflorus apresentou a mais ampla distribuição e Myrcianthes pungens a mais restrita, com ocorrência exclusiva para a margem esquerda do rio Paraná e seu tributário, o ribeirão São Pedro. Para cada espécie foram apresentadas ilustrações, descrições e chaves de identificação.
\end{abstract}

Palavras-chave: Myrtaceae, Eugeniinae, florística, vegetação ripária, rio Paraná

\begin{abstract}
The genera Calycorectes O. Berg, Hexachlamys O. Berg, Myrcianthes O. Berg, Myrciaria O. Berg and Plinia L. (Myrtaceae) in the Upper Paraná River floodplain, Brazil). The objective of the present study was to survey the species of Calycorectes O. Berg, Hexachlamys O. Berg, Myrcianthes O. Berg, Myrciaria O. Berg and Plinia L. in the Upper Paraná River floodplain, located in Mato Grosso do Sul and Paraná states (22 $40^{\prime}$ to $22^{\circ} 55^{\prime} \mathrm{S}$ and $53^{\circ} 10^{\prime}$ to $53^{\circ} 40^{\prime} \mathrm{W}$ ), Brazil. The study area, under domain of the Submontane Semidecidual Seasonal Forest, include riparian formations of the Paraná River and its islands and tributaries. The species registered were Calycorectes psidiiflorus (O. Berg) Sobral, Hexachlamys edulis (O. Berg) Kausel \& D. Legrand, Myrcianthes pungens (O. Berg) D. Legrand, Myrciaria delicatula (DC.) O. Berg, M. cuspidata O. Berg, Plinia rivularis (Cambess.) Rotman and P. trunciflora (O. Berg) Kausel. The months of major flowering and fructification were, respectively, September and November 2000 and 2001. Calycorectes psidiiflorus has the largest distribution in the study area, and Myrcianthes pungens the more limited, exclusively on the left banks of the Paraná River, and its tributary, the São Pedro Stream. For each species illustrations, descriptions, and identification keys are given.
\end{abstract}

Key words: Myrtaceae, Eugeniinae, floristics, riparian vegetation, Paraná River

\section{Introdução}

A família Myrtaceae compreende as subfamílias Leptospermoideae e Myrtoideae, sendo que a primeira possui maior concentração na Austrália. A segunda, distribuindo-se principalmente nas Américas do Sul e Central (Briggs \& Johnson 1979), apresenta apenas a tribo Myrteae e três subtribos, Myrciinae, Eugeniinae e Myrtinae, que reúnem aproximadamente 70 gêneros e 2.400 espécies (McVaugh 1968). Constituí-se numa das famílias de melhor representatividade nas diferentes formações vegetacionais do Brasil. Diversos autores têm ressaltado a elevada riqueza específica da família e a importância fitossociológica de suas espécies para as florestas do Sul e Sudoeste do Brasil (Mori et al. 1983; Klein 1984; Leitão-Filho 1993; Barroso \& Peron 1994; Soares-Silva 2000). Em ambientes ripários, incluindo a planície alagável do alto rio Paraná, essa importância também tem sido destacada, especialmente quanto à riqueza específica (Nakajima et al. 1996; Souza et al. 1997; Campos et al. 2000; Rodrigues \& Nave 2000; Romagnolo \& Souza 2000).

\footnotetext{
Parte da Tese de Doutorado da primeira Autora, Apoio Financeiro PELD/CNPq/UEM/Nupelia

2 Unviversidade Paranaense Campus Paranavaí, Avenida Humberto Bruning, 360, CEP 87706-030, Paranavaí, PR, Brasil

3 Universidade Estadual de Maringá, Nupélia, Departamento de Biologia, Avenida Colombo, 5790, CEP 87020-900, Maringá, PR, Brasil (conceição@nupelia.uem.br)

4 Autor para correspondência: mariza@unipar.br
} 
A taxonomia da família, entretanto, continua complexa e suas espécies são de difícil classificação e delimitação (McVaugh 1968; Barroso 1994 e Kawasaki 1989) o que torna freqüente a citação de elevado número de táxons indeterminados nos levantamentos florísticos e fitossociológicos. Desta forma, o presente trabalho, que faz parte do estudo da família Myrtaceae na planície alagável do alto rio Paraná, tem por objetivo realizar o levantamento das espécies de Calycorectes, Hexachlamys, Myrcianthes, Myrciaria e Plinia para essa região.

\section{Material e métodos}

A área de estudo inclui ilhas, áreas marginais e tributários do alto rio Paraná, na região denominada planície alagável. Localiza-se nos municípios de Porto Rico, São Pedro do Paraná e Marilena, no Estado do Paraná; e Bataiporã, Jateí e Taquaruçu, no Mato Grosso do Sul, tendo como limites aproximados $22^{\circ} 40^{\prime}$ a $22^{\circ} 55^{\prime} \mathrm{S}$ e $53^{\circ} 10^{\prime}$ a $53^{\circ} 40^{\prime} \mathrm{W}$. O rio Paraná, nesse trecho, apresenta padrão geomorfológico multicanal e abriga diversos subambientes fluviais, tais como pântanos, lagoas, canais secundários e diques marginais, formando extensa planície de inundação que se desenvolve na margem direita. A margem esquerda, por outro lado e na maioria das vezes, apresenta barrancos altos e estáveis de até $15 \mathrm{~m}$ de altura (Souza Filho \& Stevaux 1997).

O clima da região, de acordo com a classificação de Köppen, é do tipo Cfa (Maack 1968; Paraná 1987). As chuvas distribuem-se durante todos os meses do ano, com maior volume no período de setembro a dezembro e menor, de junho a agosto, sendo sempre superiores a $30 \mathrm{~mm} / \mathrm{mês}$ (Iapar 1994). O relevo é caracterizado pelas áreas planas da planície, com altitude variando entre 230 a 290m (Stevaux 1994). A ocorrência de Latossolos Vermelho Distrófico de textura média, de Alissolos de textura média e de Gleissolos é citada para a margem esquerda, enquanto que solos aluviais eutróficos de textura argilosa, classificados como Neossolos, são citados para a margem direita (Embrapa 1984; 1999). A vegetação ripária, descrita mais sucintamente por Souza et al. (1997; 2004) encontra-se entre o domínio da Floresta Estacional Semidecidual e do Cerrado, apresentando formações florestais e várzeas, além de vastas extensões de pastagem.

O material estudado, proveniente de coletas mensais realizadas nos anos de 1999 a 2002, foi incorporado ao acervo do HUM. Foram incluídos também os materiais pertencentes ao HUM e consultadas as coleções do FUEL e MBM. A nomenclatura utilizada para morfologia foliar baseou-se em Hickey (1974) e Radford et al. (1974) e para inflorescência, em Briggs \& Johnson (1979).

\section{Resultados e discussão}

Para a planície alagável do alto rio Paraná, as Myrtaceae da subtribo Eugeniinae O. Berg, foram registradas com a ocorrência de seis gêneros e 17 espécies, sendo Myrciaria O. Berg e Plinia L. com duas espécies cada, Calycorectes O. Berg, Hexachlamys O. Berg e Myrcianthes O. Berg, com apenas uma. Eugenia L., o mais rico, com 10 espécies, será tratado em trabalho separado. Landrum \& Kawasaki (1997), apresentando descrição sucinta desses gêneros, citaram a ocorrência de oito, para essa subtribo no Brasil, dentre os quais somente Siphoneugena O. Berg e Neomitranthes (Kausel) D. Legrand não foram encontrados na área de estudo.

\section{Chave para identificação dos gêneros de Eugeniinae}

1. Hipanto elevado sobre o ovário

2. Botões florais abertos; profilos conatos; hipanto circunciso; cálice decíduo após a maturação do fruto

2. Botões florais parcialmente fechados, abrindo-se pelo rasgamento regular ou irregular do cálice; profilos livres; hipanto não circunsiso; cálice não decíduo após a maturação no fruto

3. Lóculos biovulados; cotilédones livres entre si Plinia

3. Lóculos multiovulados; cotilédones concrescidos entre si Calycorectes

1. Hipanto não elevado sobre o ovário; cálice persistente

4. Cálice com 5 sépalas; lóculos bi a triovulados; testa lenhosa Hexachlamys

4. Cálice com 4 sépalas; lóculos geralmente multiovulados; testa membranácea

5. Embrião de cotilédones livres entre si Myrcianthes

5. Embrião de cotilédones concrescidos entre si Eugenia 
1. Calycorectes O. Berg, Linnaea 27: 317. 1854.

Espécie tipo: Calycorectes grandiflorus O. Berg

Gênero com cerca de 18 espécies distribuídas do México até a América do Sul, com maior número de representantes na Amazônia, Sul do Brasil, Paraguai e Argentina, sendo raro no Uruguai (Legrand \& Klein 1972; Rotman 1982). Próximo a Eugenia, com o qual Landrum \& Kawasaki (1997) sugeriram a união. McVaugh (1968), entretanto, os considerou distintos por Calycorectes apresentar hipanto elevado acima do ovário, botões fechados que se abrem de forma irregular e, ainda, pelas anteras lineares ou oblongas e semelhantes às de Eugenia feijoi O. Berg. Essa espécie, segundo o mesmo autor, seria um elo entre os dois gêneros. A única espécie deste levantamento, C. pisidiiflorus, diferencia-se de Eugenia, devido, principalmente, aos seus botões parcialmente fechados pela concrescência dos lobos calicinais que se rasgam irregularmente na antese.

Calycorectes psidiiflorus (O. Berg) Sobral, Candollea 40(2): 636-637. 1985.

Eugenia psidiiflora O. Berg, 1857; Calycorectes riedelianus $\mathrm{O}$. Berg, 1859.

Fig. 1.

Arbusto a arvoreta, ca. 3-10m alt. Ramos glabros, esfoliantes em placas longitudinais irregulares, castanho-acinzentados; os mais jovens comprimidos lateralmente, pubescentes. Folhas elípticas a ovadas; base obtusa a aguda; ápice agudo a acuminado; margem lisa, freqüentemente revoluta; lâmina (15-)25-55×(05-)15-20mm, razão foliar 1,5-2,8, membranácea a cartácea, concolor a discolor, glabra, excepcionalmente com pêlos apenas na nervura central, duplo-limbinérvea; nervura central adaxialmente sulcada e abaxialmente proeminente; pecíolo 4-6mm compr., sulcado adaxialmente, pubérulo. Flores 2-6, em racemos axilares ou terminais; eixo $2-4 \mathrm{~mm}$ compr. até quase ausente, piloso; ferofilos triangulares, pardacentos, pubescentes; antopódio 10-35mm compr., glabro, brilhante, esverdeado no material herborizado; profilos ca. $1,4 \times 0,9 \mathrm{~mm}$, ovados, ápice agudo, persistentes; botões florais 4-6mm compr. globosos, fechados parcialmente pela concrescência dos lobos calicinais que se rasgam irregularmente na antese em 4 lobos; lobos do cálice desiguais, os maiores ca. $3,8 \times 3,8 \mathrm{~mm}$, os menores ca. $2,5 \times 2,8 \mathrm{~mm}$, ovados, ápice obtuso; pétalas 4 , ca. $7,5 \times 6,5 \mathrm{~mm}$; disco estaminal glabro, quadrangular; estames de 4-6mm compr.; hipanto glabro, pouco elevado; estilete 5-7mm compr., glabro; ovário bilocular, lóculos multiovulados. Frutos globosos, 10-20mm diâm., vermelho-escuros quando maduros. Sementes castanho-claras, rugosas, com óvulos abortados aderidos à parede do ovário; testa quebradiça; embrião de cotilédones conferruminados.

Nomes populares: guaramirim-de-riedel, cambuí.

Material examinado selecionado: BRASIL. Mato Grosso do Sul: Bataiporã, rio Baía, 25/IX/2000, fl., M.B. Romagnolo 592 (HUM); Jateí, rio Ivinheima, 24/VIII/1999, fl., M.B. Romagnolo 376 (HUM); 14/II/2001, fr., M.B. Romagnolo 710 (HUM); Taquaruçu, rio Baía, 6/IX/1999, fl., M.B. Romagnolo 410 (HUM); 15/III/2000, fr., M.B. Romagnolo 485 (HUM). Paraná: Porto Rico, rio Paraná, 19/III/1999, fr., M.B. Romagnolo 314 (HUM); 22/VII/1999, fl., M.B. Romagnolo 328 (HUM); 23/VII/1999, fl., fr., M.B. Romagnolo 350 (HUM); ribeirão São Pedro, 11/XI/2001, fr., M.B. Romagnolo 316 (HUM); São Pedro do Paraná, ribeirão São Pedro, 16/X/1999, fl., fr., M.B. Romagnolo 422 (HUM).

Caracteres diagnósticos - C. psidiiflorus apresenta folhas de cartáceas à coriáceas e quase avenais e opacas em ambas as faces. O par de nervuras secundárias basais se fecham em laços apenas a partir da metade superior da folha formando uma nervura marginal.

Ecologia - Foram encontradas flores de janeiro a março e de julho a novembro; e frutos em fevereiro, março e de setembro a dezembro, sendo esta a espécie que maior número de meses abrangeu em estádio reprodutivo e também a que mais ampla distribuição alcançou na área. Densas populações de indivíduos arbustivos e com cerca de $2 \mathrm{~m}$ alt. foram observados nos terrenos íngremes da margem esquerda do rio Paraná. Por outro lado, indivíduos com cerca de 8-10m alt., isolados e reunindo grande quantidade de juvenis no subosque estiveram presentes nos remanescentes florestais menos perturbados.

Distribuição geográfica: no Brasil, sua ocorrência é citada para os Estados da Bahia, Minas Gerais, Rio de Janeiro, São Paulo, Paraná, Santa Catarina e Rio Grande do Sul, alcançando, também a Argentina, Paraguai e Uruguai (Legrand \& Klein 1972; Rotman 1982; Soares-Silva 2000).

2. Hexachlamys O. Berg, Linnaea, 27: 345. 1856.

Espécie tipo: Hexachlamys humilis O. Berg

Gênero com cerca de 10 espécies distribuídas no Brasil, pelas regiões Sul e Sudeste, no Paraguai, 


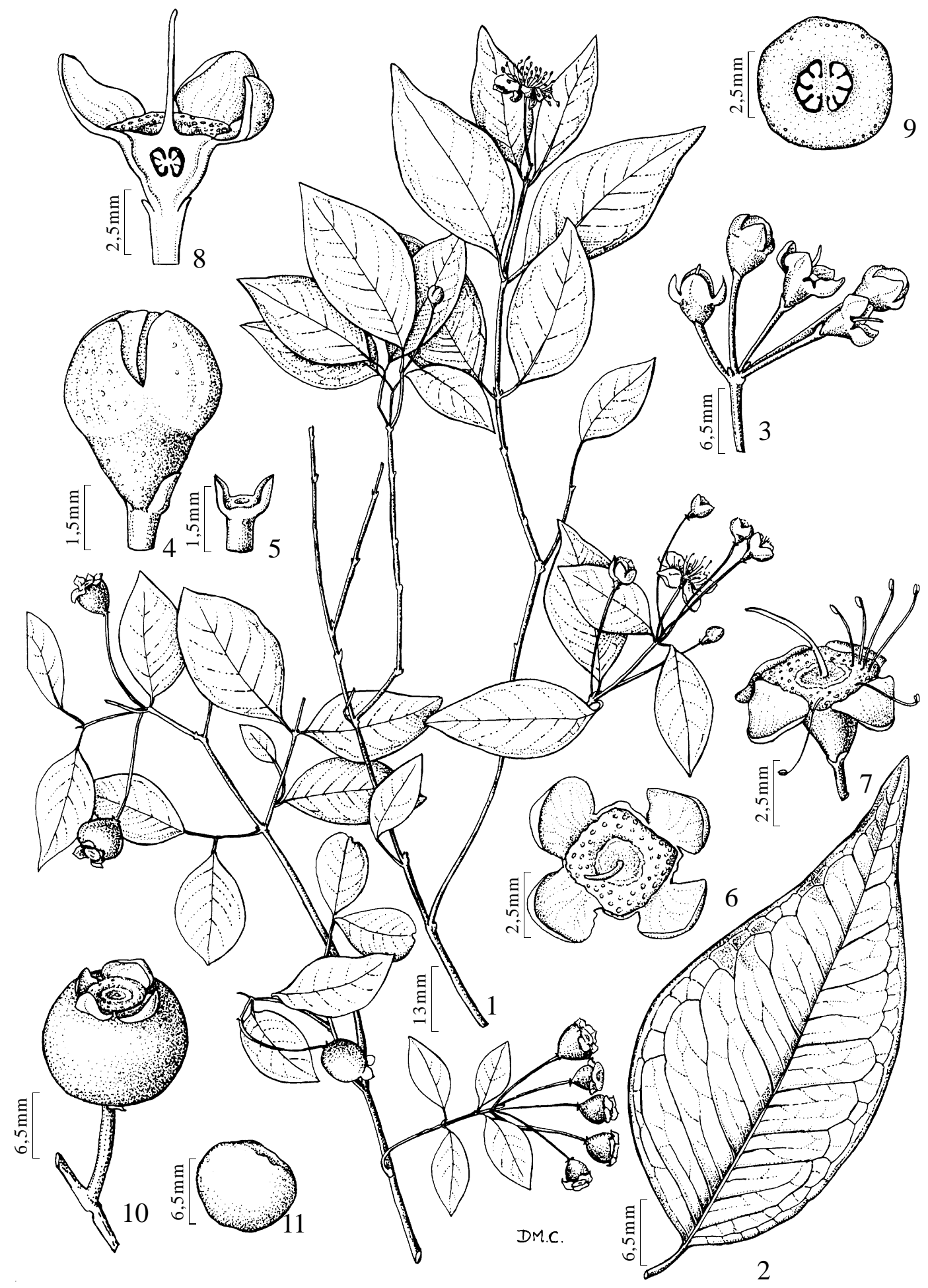

Figura 1. Calycorectes psidiiflorus O. Berg. Sobral - 1. Hábito. 2. Folha. 3. Inflorescência. 4. Botão floral. 5. Profilos. 6. Disco estaminal, vista frontal. 7. Disco estaminal, vista lateral. 8. Flor em corte longitudinal. 9. Ovário em corte transversal. 10. Fruto. 11. Embrião (M.B. Romagnolo, 350). 
Argentina e Uruguai (Mc Vaugh 1968; Legrand \& Klein 1972). McVaugh (1968) considerou este gênero independente, que se distingue de Eugenia por apresentar flores pentâmeras ou hexâmeras e radícula exserta. A única espécie deste levantamento, H. edulis, diferencia-se das espécies de Eugenia por apresentar flores pentâmeras, sementes com testa lenhosa e radícula exserta.

Hexachlamys edulis (O. Berg) Kausel \& D. Legrand, Darwiniana 9(2): 302. 1950.

Myrcianthes edulis O. Berg, 1857; Eugenia edulis Benth. \& Hook, 1879; Eugenia myrcianthes Nied., 1893.

Fig. 2.

Arvoreta a arbórea, ca.8-15m alt. Ramos glabros, pouco esfoliantes, castanho-acinzentados; os mais jovens comprimidos lateralmente, densamente pilosos; pêlos simples, hialinos, 1,0-1,5mm compr. Folhas ovadas a elípticas; base obtusa a aguda; ápice agudo a levemente acuminado às vezes apiculado; margem pouco cartilagínea, ciliada; lâmina 40-90× $15-25 \mathrm{~mm}$, razão foliar 2,2-2,6, membranácea a coriácea, concolor a discolor, face abaxial freqüentemente opaca, velutinoserícea, glabrescente com a idade; nervura central adaxialmente plana, abaxialmente proeminente, com pêlos longos e hialinos; nervuras marginais não definidas; pecíolo 8-10mm compr., denso piloso. Flores 3-7, excepcionalmente uma, em racemos curtos, freqüentemente em ramos jovens com folhas novas; eixo muito reduzido a ausente, albo-tomentoso; ferofilos alongados; antopódio 3-10mm compr.; profilos ca. $3 \times 0,9 \mathrm{~mm}$, lineares, ápice agudo, caducos; botões florais 5-7mm compr., globosos, denso albo-tomentosos; sépalas 5 , semelhantes, ca. $2,8 \times 2,8 \mathrm{~mm}$, às vezes 3 maiores e 2 menores, triangulares, ápice agudo; pétalas 5 , ca. $8 \times 5 \mathrm{~mm}$; disco estaminal albo-tomentoso, pentagonal; estames 4-7mm compr.; hipanto albotomentoso, pouco elevado acima do ovário; estilete 6-7mm compr., piloso na metade inferior; ovário bilocular; lóculos bi a triovulados. Frutos oblongos, 10-45×7-35, albo-seríceos quando jovens, amarelos quando maduros. Sementes 1-3, castanho-claras; testa lenhosa; embrião de cotilédones conferruminados e radícula exserta.

Nomes populares: pêssego-do-mato, cereja-do-riogrande, ubajaí, ibajaí e ivaí.

Material examinado: BRASIL. Mato Grosso do Sul: Bataiporã, rio Baía, 25/IX/2000, fr., M.B. Romagnolo 586 (HUM); Jateí, rio Ivinheima, 18/IX/1994, fl., fr. M.B. Romagnolo 301 (HUM);
Taquaruçu, rio Paraná, 30/V/1996, fl., M.B. Romagnolo 84 (HUM); rio Baía, 30/IX/2000, fr., M.B. Romagnolo 656 (HUM); canal Corutuba, 6/IX/1999, fr., M.B. Romagnolo 400 (HUM); 30/IX/2000, fr., M.B. Romagnolo 659 (HUM); rio Ivinheima, 15/V/2000, fl., M.B. Romagnolo 513 (HUM). Paraná: Marilena, rio Paraná, 8/VIII/2000, fl., M.C. Souza 815 (HUM).

Caracteres diagnósticos - H. edulis, diferentemente das demais Myrtaceae deste levantamento, apresenta súber rugoso, fissurado e não esfoliante. Suas folhas jovens são membranáceas e densamente pilosas, enquanto que as adultas são coriáceas e com pêlos na face abaxial. Durante a fase de reprodução é comum a caducifolia com a presença de muitas gemas albotomentosas protegendo as futuras inflorescências. Apresenta cálice reflexo na antese e hipanto elevado no fruto jovem.

Ecologia - foram observadas flores em maio, agosto e setembro e frutos em setembro e outubro. $\mathrm{Na}$ área de estudo foi encontrada, com mais freqüência, na margem direita do rio Paraná e de seus afluentes, rios Baía e Ivinheima, tanto em remanescentes florestais como em pastagens. Essas áreas, com diferentes estágios de perturbação, encontram-se próximas do Cerrado, o que corrobora com observações feitas por outros autores (Legrand 1968; Legrand \& Klein 1977; Rotman 1982; Lorenzi 1998; Soares-Silva 2000), que consideram esta, uma espécie característica de formações secundárias das Florestas Estacionais Semideciduais da bacia do rio Paraná e do Cerrado. Além de ornamental, destacase pelos frutos atrativos e comestíveis, consumidos pela fauna e apreciados pelo homem, tanto ao natural como na forma de doces, sucos e geléias (Lorenzi 1998).

Distribuição geográfica: apresenta ocorrência registrada para os Estados do Minas Gerais, Mato Grosso do Sul, Paraná, Santa Catarina e Rio Grande do Sul chegando até o Paraguai, norte e nordeste da Argentina e Uruguai (Legrand 1968; Legrand \& Klein 1977; Rotman 1982; Lorenzi 1998; Soares-Silva 2000).

\section{Myrcianthes O. Berg, Linnaea 27:315. 1856.}

Espécie tipo: Myrcianthes apiculata O. Berg

Gênero com cerca de 50 espécies nativas da região neotropical, principalmente da América do Sul, sendo três registradas para as regiões Sul e Sudeste do Brasil (Landrum \& Kawasaki 1997), das quais apenas uma o foi no presente estudo. 

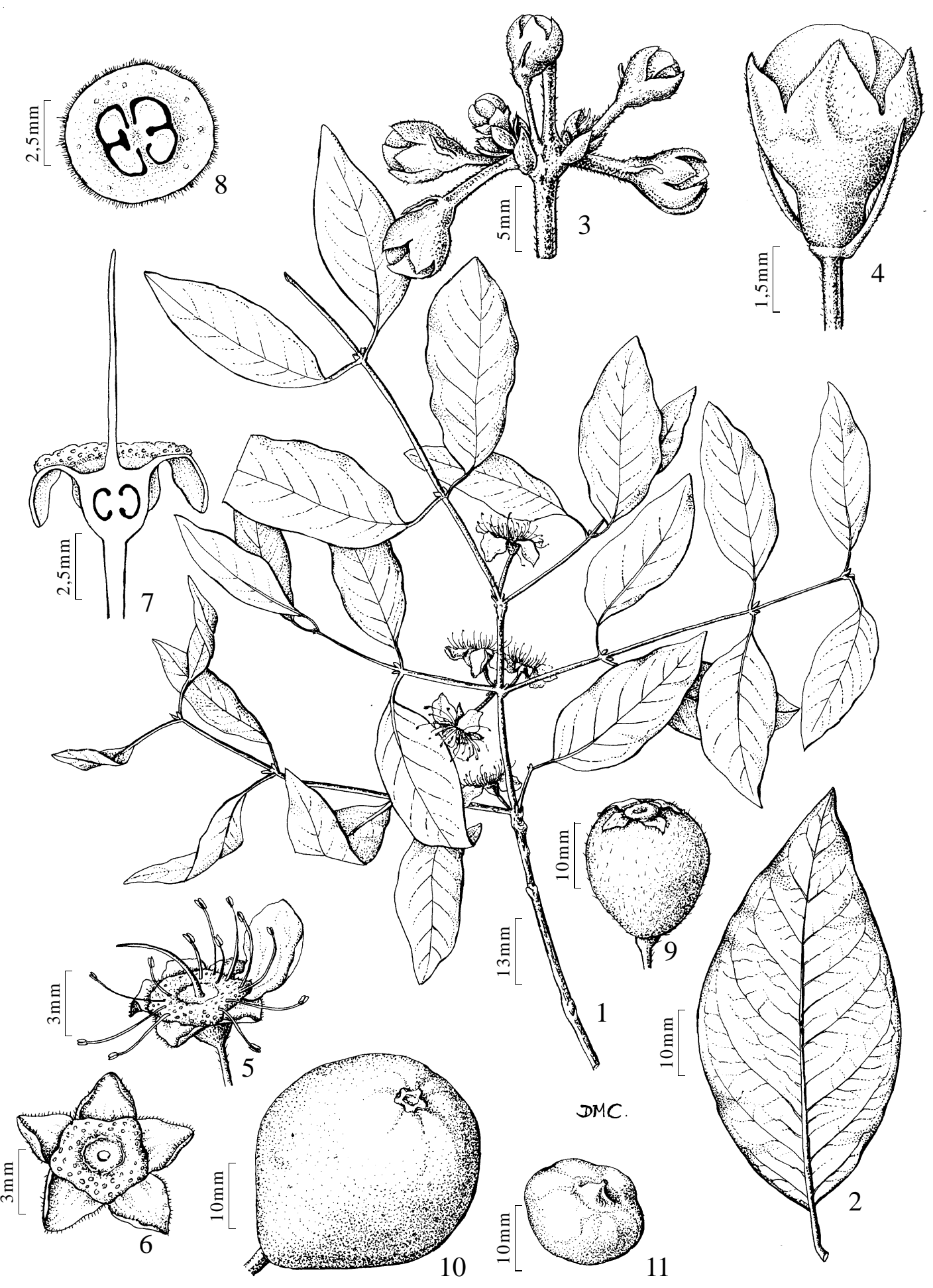

Figura 2. Hexachlamys edulis (O. Berg) Kausel \& D. Legrand - 1. Hábito. 2. Folha. 3. Inflorescência. 4. Botão floral. 5. Disco estaminal, vista lateral. 6. Disco estaminal, vista frontal. 7. Flor em corte longitudinal. 8. Ovário em corte transversal. 9. Fruto jovem. 10. Fruto maduro. 11. Embrião (M.B. Romagnolo, 301). 
Myrcianthes pungens (O. Berg) D. Legrand, Boletim de la Falculdade de Agronomia de la Republica, Montevideo 101:52. 1968.

Eugenia pungens O. Berg, 1857; Acreugenia pungens (O. Berg) Kausel, 1956; Eugenia pungens O. Berg, 1857.

Fig. 3.

Arvoreta, ca. 2-4m alt. Ramos pilosos, esfoliantes, pardacentos, mais raramente castanho-acizentados; os mais jovens denso albo-seríceo; pêlos simples, 1,0-1,5mm compr. Folhas elípticas a ovadas; base aguda, raramente obtusa; ápice agudo a acuminado, pungente; margem lisa a ondulada, cartilagínea, ciliadas quando jovens; lâmina (-25)50-85×10-45mm, razão foliar 1,5-3,0, cartácea quando joven, coriácea quando madura, discolor, face adaxial verde-brilhante, face abaxial argentea a parda, pilosa a glabrescente com a idade, limbinérveas; nervura central adaxialmente canaliculada, abaxialmente proeminente e pilosa; pecíolo 4-6mm compr., adaxialmente sulcado, esparso piloso. Flores isoladas, raramente em dicásio; axilares a terminais; ferofilos lanceolados, ápice agudo; antopódios 25-35mm compr., denso pilosos; profilos ca. 3,8×1,0mm, lineares, ápice agudo, caducos; botões florais 6,0-7,0mm compr., abertos; sépalas 4, desiguais, 2 maiores ca. $4,8 \times 5,8 \mathrm{~mm}, 2$ menores ca. $3,3 \times 5,8 \mathrm{~mm}$, ovadas, ápice obtuso nas maiores e agudo nas menores; pétalas 4 , ca. $7 \times 7 \mathrm{~mm}$, base engrossada; disco estaminal esparso seríceo, quadrangular; estames $6-11 \mathrm{~mm}$ compr., glabros; hipanto albo denso-seríceo, não elevado; estilete 6-7mm compr., piloso na base; ovário bilocular, lóculos multiovulados (ca. 30 óvulos). Frutos não observados.

Nomes populares: guabiju, guabirá, gutiguli, mato blanco e guabira-guaçu.

Material examinado: BRASIL. Paraná: Porto Rico, rio Paraná, 21/I/2000, fr., M.B. Romagnolo 455 (HUM); 10/II/2000, fr., M.B. Romagnolo 471 (HUM); 25/X/2000, fl., M.B. Romagnolo 686 (HUM); São Pedro do Paraná, ribeirão São Pedro, 24/VIII/2001, vgt., M.B. Romagnolo 304 (HUM).

Caracteres diagnósticos - M. pungens diferencia-se das demais espécies de Myrtaceae deste estudo, por apresentar folhas coriáceas, brilhantes, de coloração verde escura e ápice cuspidado e pungente.

Ecologia - foram observadas flores em setembro e outubro e frutos jovens em janeiro e fevereiro. Poucos indivíduos foram registrados na área e a distribuição foi restrita à margem esquerda do rio Paraná e ao ribeirão São Pedro, sobre solos rochosos. Outros autores (Legrand 1968; Marchiori \& Sobral 1997) também observaram a preferência desta espécie por solos úmidos e rochosos. Apresenta potencial apícola e frutos comestíveis, muito apreciados pela avifauna. É uma espécie de crescimento lento e produz madeira dura e resistente, podendo ser empregada na arborização, além de ser indicada para plantios mistos com fins preservacionistas (Legrand \& Klein 1977; Rotman 1979; Lorenzi 1998).

Distribuição geográfica: essa espécie distribui-se desde o Estado de São Paulo até o norte do Uruguai, alcançando a Bolívia, Paraguai e a Argentina (Rotman 1979; Marchiori \& Sobral 1997; Soares-Silva 2000).

\section{Myrciaria O. Berg, Linnaea 27: 3201856.}

\section{Espécie tipo: Myrciaria tenella (DC.) O. Berg}

Gênero com número incerto de espécies, distribuídas desde o México e Caribe até o Uruguai (Sobral 1993). No Brasil ocorrem cerca de 30 espécies, principalmente na região Sudeste (Landrum \& Kawasaki 1997).

Kausel (1966) inclui em Paramyrciaria Kausel, os táxons que apresentam hipanto decíduo após a antese e embriões com cotilédones livres e, em Myrciaria, aqueles com hipanto decíduo e embrião com cotilédones conferruminados. Essa separação foi, também, adotada por Rotman (1982; 1986) e Sobral (1991; 1993). Outros autores, como McVaugh (1968), Legrand \& Klein (1978), Soares-Silva (2000), acreditaram que as variações nos cotilédones eram devidas ao estágio de maturação e não aceitaram a divisão do gênero, mantendo apenas Myrciaria, posição essa também adotada no presente estudo.

Chave para identificação das espécies de Myrciaria

1. Folhas com mais de $20 \mathrm{~mm}$ compr., ápice nunca apiculado, nervuras secundárias de 12-16 pares com ângulo de divergência $50^{\circ}-60^{\circ}$ M. delicatula

1. Folhas até $20 \mathrm{~mm}$ compr., ápice apiculado, nervuras secundárias de 8-12 pares com ângulo de divergência $30^{\circ}-40^{\circ}$. M. cuspidata

Myrciaria delicatula (DC.) O. Berg, Flora Brasiliensis 14(1): 362. 1857.

Eugenia delicatula DC., 1828; Myrciaria linearifolia O. Berg, 1857; Eugenia maschalantha Kiaerskou, 1893; Myrciaria micrantha Barb. Rodr. 
1907; Paramyrciaria delicatula (DC.) Kausel,1967; Myrciaria maschalantha (Kiaerskou) Mattos \& D. Legrand, 1975.

Fig. 4.

Arbusto a árvore, ca. 3-20m alt. Ramos glabros, esfoliantes em pequenas placas longitudinais pardacentas com pontos translúcidos, castanhoavermelhados; os mais jovens pubescentes; pêlos simples. Folhas elípticas; base aguda; ápice agudo a atenuado; margem lisa, pouco revoluta; lâmina 20-40×5-10mm, razão foliar 3,0-6,7, cartácea, concolor, glabra, às vezes com pêlos apenas na nervura central, limbinérvea; nervura central adaxialmente plana, abaxialmente proeminente, às vezes mais claras que o limbo; pecíolo 3-4mm compr., pubescente a glabro, castanho-avermelhado. Flores 3-5, sésseis, em glomérulos axilares, eixo ausente; ferofilos ovados, ápice agudo; antopódios ausentes; profilos ca. $1,4 \times 1,4 \mathrm{~mm}$, ovados, ápice agudo, bases conatas, persistentes; botões florais $1,5-2 \mathrm{~mm}$ compr., abertos; sépalas 4 , semelhantes, ca. $1,4 \times 1,5 \mathrm{~mm}$, ovadas, ápice obtuso; pétalas 4 , ca. $1,9 \times 1,4 \mathrm{~mm}$; disco estaminal glabro, globuloso; estames 3-4mm compr., glabros; hipanto externamente albo-tomentoso, internamente pubescente, prolongado acima do topo do ovário, decíduo após a antese por cisão transversal junto ao anel de estames; estilete 4-5mm compr., glabro; ovário bilocular, biovular, óvulos basais. Frutos globosos, 6-10mm diâm., alaranjados a vermelhos quando maduros, coroados por cicatriz circular. Sementes 1-2, castanhas claras; testa lisa, brilhante; embrião de cotilédones carnosos, livres.

Nomes populares: cambuí, cambuim e camboí.

Material examinado: BRASIL. Mato Grosso do Sul: Bataiporã, rio Baía, 25/IX/2000, fr., M.B. Romagnolo 581 (HUM); Jateí, rio Ivinheima, 16/VI/2000, fl., fr., M.B. Romagnolo 536 (HUM); Taquaruçu, rio Baía, 14/VI/2000, fr., M.B. Romagnolo 506 (HUM); canal Corutuba, 30/IX/2000, fr., M.B. Romagnolo 645 (HUM). Paraná: Marilena, rio Paraná, 14/II/2001, vgt., M.B. Romagnolo 707 (HUM).

Caracteres diagnósticos - $M$. deliculata caracteriza-se por apresentar caule com ritidoma muito esfoliante, desprendendo-se em lâminas finas e compridas, além de densamente ramificado e com grande quantidade de folhas pequenas, verdes escuras.

Ecologia - foram observados flores em junho e frutos em junho, julho e setembro. Rotman (1982) e SoaresSilva (2000) observaram fases de reprodução por maior período de tempo. Na área deste estudo foi observada tanto nos subsistemas da margem direita do rio Paraná (Mato Grosso do Sul), como da margem esquerda (Paraná), sendo que neste último, ocorreu somente próximo à foz do rio Paranapanema. Nos remanescentes florestais alcançam cerca de $20 \mathrm{~m}$ de altura e formam densas populações de indivíduos jovens de 1 a $2 \mathrm{~m}$ de altura, enquanto que nas áreas abertas, geralmente de pastagem, formam aglomerados de indivíduos perfilhados. Segundo Bernardi (1985) essa espécie comporta-se como ciófita e seletiva higrófita, comum nas matas de galeria.

Distribuição geográfica: esta espécie foi registrada para os Estados de Santa Catarina, Paraná (Bacia do Rio Tibagi), Mato Grosso do Sul e para o Paraguai (Legrand \& Klein 1978; Bernardi 1985; Soares-Silva 2000).

Myrciaria cuspidata O. Berg, Flora Brasiliensis 14(1): 367. 1857

Myrciaria herbacea O. Berg, 1857; Myrciaria minensis O. Berg, 1857; Eugenia alegrensis Kiaerskou, 1893; E. minensis (O. Berg) Kiaerskou, 1893; M. apiculata Barb. Rodr. ex Chodat et Hassler, 1907; M. recurvipetala Barb. Rodr. ex Chodat et Hassler, 1907.

Fig. 6A.

Arbusto a arvoreta, ca. 2-3m alt. Ramos glabros, esfoliantes, de castanho a acinzentados; os mais jovens comprimidos lateralmente, pardacentos, pilosos; pêlos simples. Folhas elípticas; base aguda; ápice agudo, apiculado; margem lisa, pouco revoluta; lâmina 10-20×4-10mm, razão foliar 1,8-3, cartácea, concolor, glabra, às vezes com pêlos apenas na nervura central, limbinérvea; nervura central adaxialmente plana, abaxialmente pouco proeminente; pecíolo $1-2 \mathrm{~mm}$ compr., pubescente a glabro, os mais velhos castanhoavermelhados. Flores e frutos não observados.

Nomes populares: cambuí, cambuim e camboí.

Material examinado: BRASIL. Paraná: Porto Rico, ribeirão São Pedro, 14/XII/2001, vgt., M.B. Romagnolo 750 (HUM).

Caracteres diagnósticos - M. cuspidata apresenta tronco geralmente de coloração castanho-avermelhada, bastante ramificado, formando copa arredondada, densa, com folhagem abundante. Suas folhas verdeescuras de tamanho reduzido e ápice cuspidado, permitem a identificação de material vegetativo.

Ecologia - pode ser considerada como uma espécie rara para a área de estudo, sendo sua ocorrência registrada apenas na margem do ribeirão São Pedro 


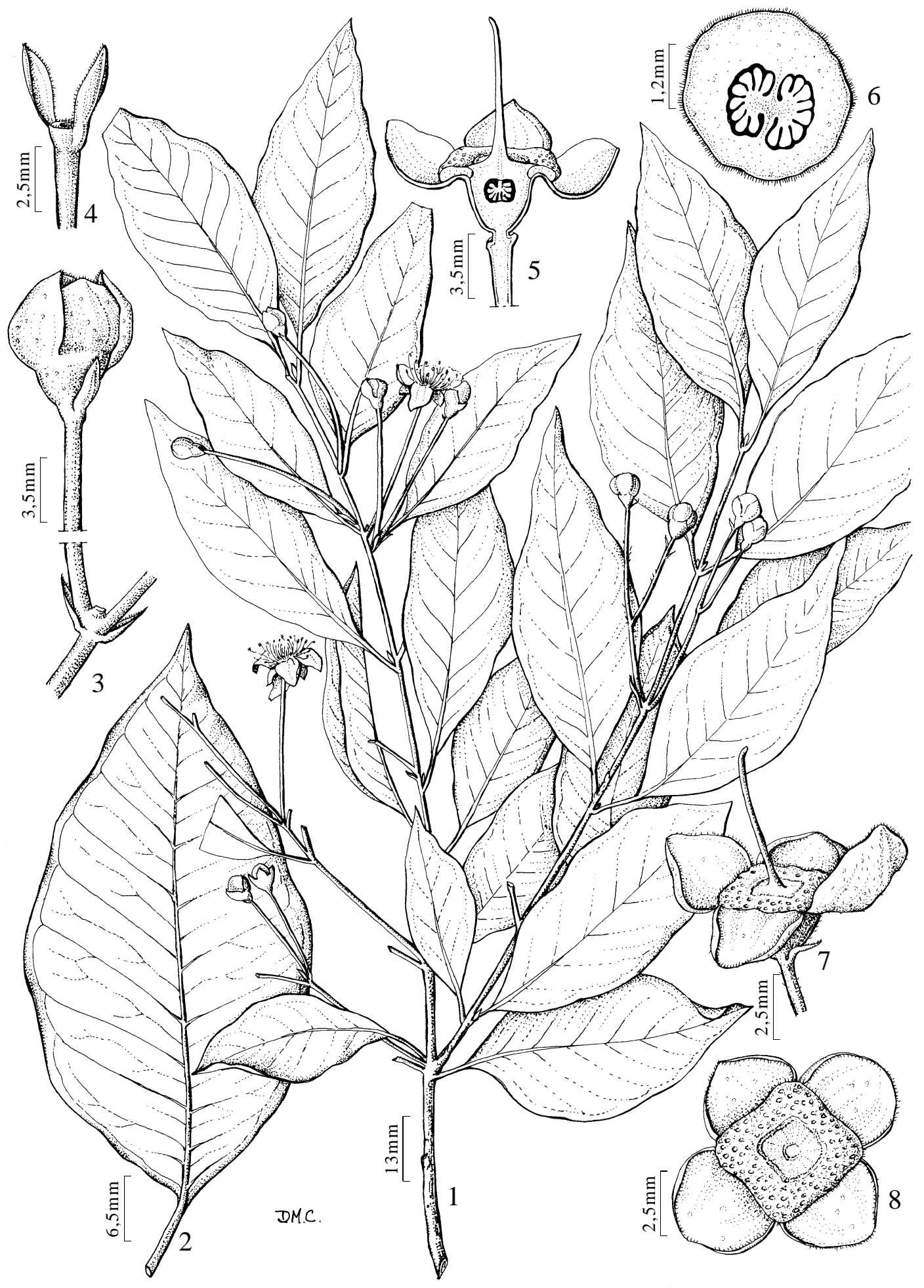

Figura 3. Myrcianthes pungens (O. Berg) D. Legrand - 1. Hábito. 2. Folha. 3. Botão floral. 4. Profilos. 5. Flor em corte longitudinal. 6. Ovário em corte transversal. 7. Disco estaminal, vista lateral. 8. Disco estaminal, vista frontal (M.B. Romagnolo, 686). 


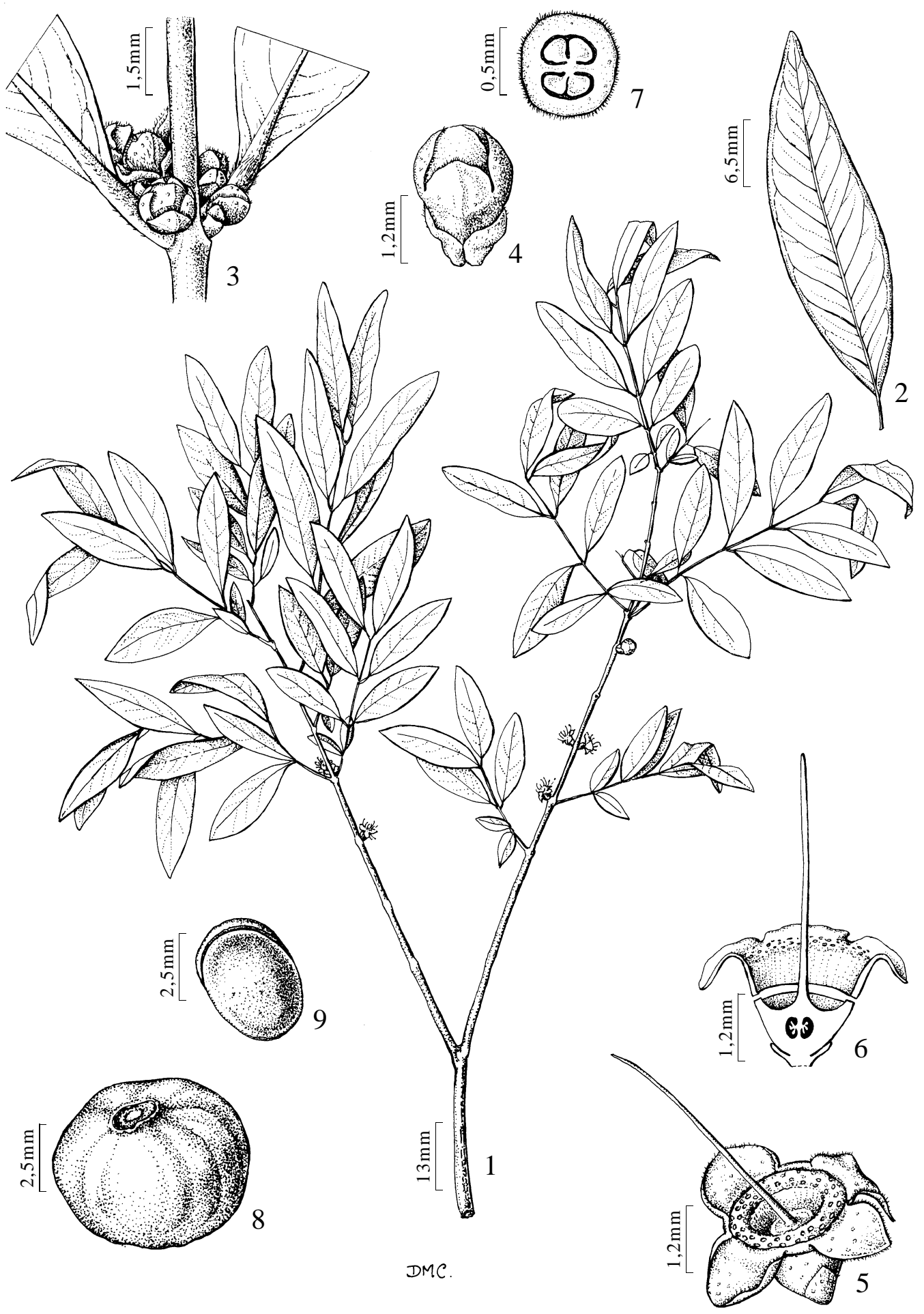

Figura 4. Myrciaria delicatula (DC.) O. Berg - 1. Hábito. 2. Folha. 3. Inflorescência. 4. Botão floral. 4. Profilos. 5. Disco estaminal. 6. Flor em corte longitudinal. 7. Ovário em corte transversal. 8. Fruto. 9. Embrião (M.B. Romagnolo, 540). 
(PR). Seus frutos são apreciados pela fauna silvestre, principalmente por aves. É encontrada com freqüência em florestas ciliares, demonstrando preferência por ambientes úmidos (Marchiori \& Sobral 1997).

Distribuição geográfica: sua ocorrência foi registrada para os Estados de Minas Gerais, São Paulo, Paraná, Santa Catarina, Paraná e Rio Grande do Sul, também para o Paraguai e Argentina (Legrand \& Klein 1978; Soares-Silva 2000).

\section{Plinia Linnaeus, Species Plantarum 516. 1753}

\section{Espécie tipo: Plinia pinnata L.}

Gênero exclusivamente das Américas Central e do Sul, com um número ainda incerto de espécies. Rotman (1982) estimou em aproximadamente 20, mas Sobral (1994), entretanto, considerou este número inferior à realidade.

\section{Chave para identificação das espécies de Plinia}

1. Pecíolos até $10 \mathrm{~mm}$ compr.; folhas de ápice agudo a acuminado, limbinérveas, nervuras marginais até $1 \mathrm{~mm}$ da borda; nervuras secundárias de 13-16 pares

P. rivularis

1. Pecíolos até $5 \mathrm{~mm}$ de compr.; folhas de ápice apiculado, duplo-limbinérveas, nervuras marginais até $2 \mathrm{~mm}$ da borda; nervuras secundárias de 10-13 pares

P. trunciflora

Plinia rivularis (Cambess.) Rotman, Bol. Soc. Argent. Bot. 24(1-2)195. 1985.

Eugenia rivularis Cambess., 1832; Myrciaria rivularis Cambess., 1856; M. baporeti D. Legrand, 1936; Myrciariopsis baporeti (D. Legrand) Kausel, 1956; Siphoneugena baporeti (D. Legrand) Kausel, 1966; Myrciaria rivularis (Cambess.) O. Berg var. baporeti (D. Legrand) D. Legrand, 1978; Plinia baporeti (D. Legrand) Rotman, 1982.

Fig. 5.

Arvoreta a árvore, ca. 8-12m alt. Ramos glabros, pouco esfoliantes, argenteos; os mais jovens comprimidos lateralmente, levemente canaliculados, esbranquiçados. Folhas elípticas a ovadas; base agudacuneada; ápice agudo a longo acuminado, às vezes cuspidado; margem revoluta; lâmina 40-75×10-30mm, razão foliar 2-4, cartácea a coriácea, concolor a discolor, face adaxial argentea em material herborizado, glabras, limbinérveas; nervura central adaxialmente plana, abaxialmente proeminente; pecíolo $8-10 \mathrm{~mm}$ compr., sulcado, glabro, às vezes rugoso. Flores 10-20, em inflorescências botrióides, axilares a terminais; eixo 30-50mm compr., castanho-escuro, piloso; ferofilos ovados, ápice agudo; antopódios 5-6mm compr.; profilos ca. $1,9 \times 0,5 \mathrm{~mm}$, lanceolados a lineares, ápice agudo, caducos; botões florais 3-4mm compr., globosos, fechados, abrindo-se pelo rasgamento dos lobos calicinais; lobos do cálice 4, semelhantes, ca. 2,4×1,4mm, ovados, ápice agudo; pétalas 4 , ca. $3 \times 2,5 \mathrm{~mm}$; disco estaminal pubérulo, crasso, quadrangular; estames 5-6mm compr., glabros; hipanto glabro, prolongado acima do ápice do ovário; estilete 6-7mm compr., pubérulo; ovário bilocular, lóculos biovulados, óvulos basais. Frutos globosos, 15-20mm diâm., amarelados até roxos quando maduros. Sementes 1-2, castanho-claras; testa lisa, brilhante; embrião de cotilédones carnosos, livres.

Nomes populares: guapuriti, baporeti e guaramirim. Material examinado: BRASIL. Mato Grosso do Sul: Taquaruçu, rio Baía, 30/IX/2000, fr., M.B. Romagnolo 651 (HUM); rio Ivinheima, 24/IX/1999, fl., fr., M.B. Romagnolo 381 (HUM). Paraná: Porto Rico, rio Paraná, 22/X/1993, fl., M. Previdelo 53 (HUM); São Pedro do Paraná, ribeirão São Pedro, 17/VI/2000, vgt., M.B. Romagnolo 550 (HUM).

Caracteres diagnósticos - $P$. rivularis diferencia-se das demais espécies deste estudo por apresentar pecíolo longo de 8-10mm de comprimento e ápice da folha longamente acuminado, bem como folhas de coloração prateada.

Ecologia - foram observadas flores de agosto a outubro e frutos em setembro. Este período de reprodução também foi observado por outros autores (Legrand \& Klein 1978; Rotman 1985). Apresenta distribuição moderada, na área de estudo, sendo encontrada principalmente em locais de vegetação pouco perturbada, como os remanescentes florestais dos rios Baía e Iviheima (Mato Grosso do Sul). Ocorre número elevado de indivíduos nos paredões de arenito (barranco) da margem esquerda do rio Paraná e também nas margens do ribeirão São Pedro. De acordo com Bernardi (1985), trata-se de uma espécie nativa da bacia do rio Paraná com ampla distribuição, porém não muito abundante, sendo comum em matas de galeria.

Distribuição geográfica: sua ocorrência foi registrada para os Estados do Rio Janeiro, São Paulo, Paraná, Santa Catarina e também para o Paraguai, Uruguai e Argentina (Rotman 1982; Soares-Silva 2000). 


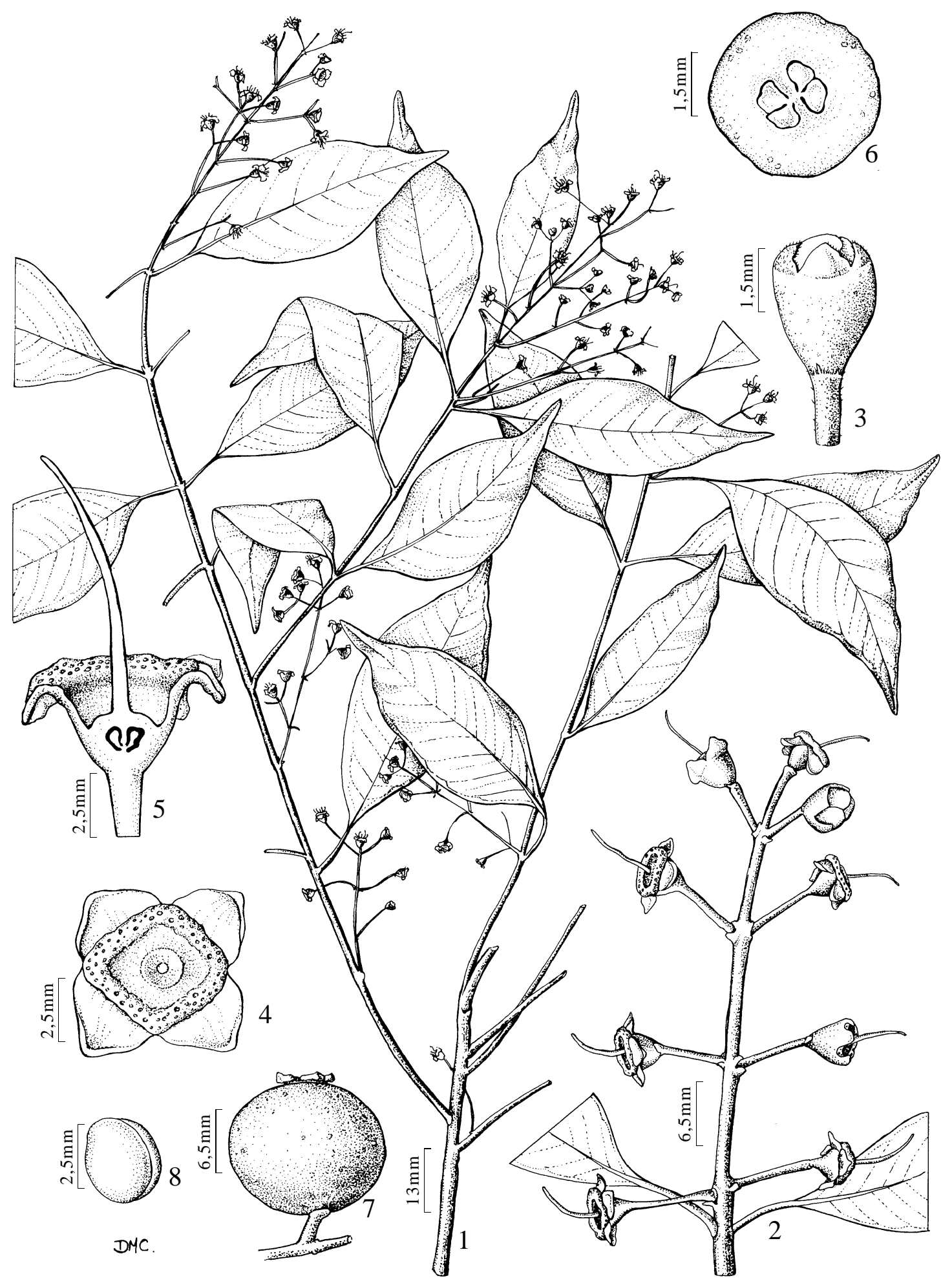

Figura 5. Plinia rivularis (Cambess.) Rotman - 1. Hábito. 2. Inflorescência. 3. Botão floral. 4. Disco estaminal. 5. Flor em corte longitudinal. 6. Ovário em corte transversal. 7. Fruto. 8. Embrião (M.B. Romagnolo, 381). 


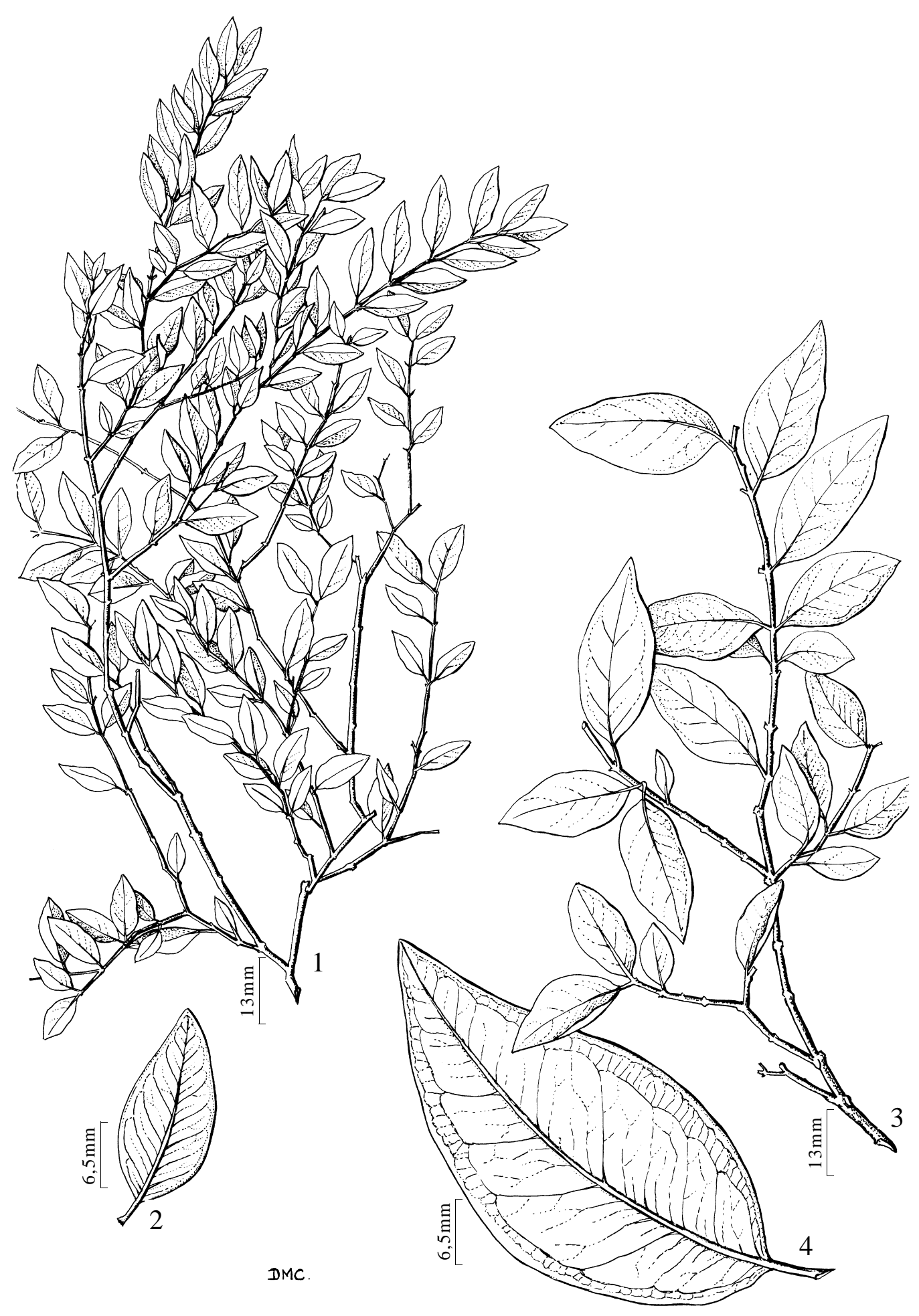

Figura 6A. Myrciaria cuspidata O. Berg - 1. Hábito. 2. Folha (M.B. Romagnolo, 750). Figura 6B. Plinia trunciflora (O. Berg) Kausel 3. Hábito. 4. Folha (M.B. Romagnolo, 719). 
Plinia trunciflora (O. Berg) Kausel, Ark. Bot. 03: 507. 1956.

Myrciaria trunciflora O. Berg, 1857; Guapurium peruvianum Poiret, 1821; Eugenia guapurium DC., 1828; Myrciaria guapurium (DC.) O. Berg, 1856; Eugenia rabeniana Kiaerskou, 1893; Myrciaria peruviana (Poiret) Mattos, 1983.

Fig. 6B.

Arvoreta, ca. 2-4m alt. Ramos pubérulos, esfoliantes, castanho-avermelhados; os mais jovens comprimidos lateralmente, pilosos; pêlos simples, ferrugíneos. Folhas elípticas a ovadas; base obtusa a aguda; ápice agudo às vezes atenuado, apiculado; margem ciliada; lâmina $15-50 \times 6-20 \mathrm{~mm}$, razão foliar 1,5-3,5, membranácea a cartácea, conconlor, glabra, duplo-limbinérvea; nervura central adaxialmente canaliculada, glabra, abaxialmente proeminente, pilosa; pecíolo 3-5mm compr., sulcado, piloso, escurecido em material herborizado. Flores e frutos não observados.

Nomes populares: jaboticabeira, jaboticabeirarajada, jaboticabeira-preta.

Material examinado: BRASIL. Mato Grosso do Sul: Jateí, rio Ivinheima, 17/VI/2000, vgt., M.B. Romagnolo 373 (HUM); Taquaruçu, rio Baía, 31/V/2001, vgt., M.B. Romagnolo 719 (HUM); Paraná: Porto Rico, rio Paraná, 17/VI/2000, vgt., M.B. Romagnolo 549 (HUM); 8/VIII/2000, vgt., M.B. Romagnolo 555 (HUM); córrego Caracu, 14/IX/2000, vgt., M.B. Romagnolo 369 (HUM); São Pedro do Paraná, ribeirão São Pedro, 16/II/1999, vgt., M.B. Romagnolo 375 (HUM); Marilena, rio Paraná, 14/II/2001, vgt., M.B. Romagnolo 707 (HUM).

Caracteres diagnósticos - P. trunciflora apresenta folha de ápice atenuado, apiculado e com nervuras marginais até $2 \mathrm{~mm}$ da borda e as nervuras intramarginais até $1 \mathrm{~mm}$ da borda, formada pelo primeiro par de nervura secundária basal que não se anastomosa.

Ecologia - na área de estudo não foram registrados indivíduos em fase reprodutiva, provavelmente por serem jovens, com cerca de $2 \mathrm{~m}$ de altura. Apresenta ampla distribuição na área, ocorrendo principalmente em remanescentes vegetais pouco perturbados, de ambas as margens do rio Paraná e de seus tributários. É cultivada em muitas regiões do Brasil e produzem frutos saborosos dos quais são produzidos licor e aguardente; a entrecasca, em cozimento, é indicada no tratamento de asma (Legrand \& Klein 1978).

Distribuição geográfica: sua ocorrência é citada desde o Estado de Minas Gerais até o Rio Grande do
Sul, também para o Paraguai e Argentina (Legrand \& Klein 1978; Rotman 1982).

\section{Agradecimentos}

Aos pesquisadores Dra. Lúcia Helena SoaresSilva (UNB) e Marcos Sobral (UFRS), pelo auxílio na identificação das espécies; aos integrantes do laboratório de Mata Ciliar do Nupélia/UEM, pela colaboração nos trabalhos de campo.

\section{Referências bibliográficas}

Barroso, G.M. 1994. Myrtaceae do Sudeste do Brasil: Espécies Novas do Gênero Plinia Linnaeus. Napaea 10: $1-5$.

Barroso, G.M. \& Peron, M.V. 1994. Myrtaceae. Pp. 261-302. In: M.P.M. Lima \& R.R.G. Bruni (orgs.). Reserva Ecológica de Macaé de Cima, Nova Friburgo: RJ. Aspectos Florísticos das Espécies Vasculares. Jardim Botânico v.1. Rio de Janeiro.

Bernardi, L. 1985. Contribuición a la dendrologia Paraguaya II. Boissieria 37: 75-151.

Briggs, B.G. \& Johnson, L.A.S. 1979. Evolution in the Myrtaceae - Evidence fron iflorescence structure. Proceedings of the Linnean Society of New South Wales 102(4): 160-250.

Campos, J.B.; Romagnolo, M.B. \& Souza, M.C. 2000. Structure, composition and spacial distribuition, tree species in a remnant of the semideciduous seasonal alluvial forest of the upper Parana river floodplain. Archives of Biology and Technology 43(2): 185-194.

Embrapa. 1984. Levantamento de reconhecimento dos solos do Estado do Paraná. Boletim técnico, t.2. Curitiba.

Embrapa. 1999. Sistema Brasileiro de Classificação de Solos. Embrapa, Brasília.

Hickey, L.J. 1974. Clasificasión de la arquitectura de las hojas de Dicotiledoneas. Boletin de la Sociedad Argentina de Botáncia 16(1-2): 1-26.

Iapar. 1994. Cartas climáticas do Estado do Paraná. Iapar, Londrina.

Kausel, E. 1966. Lista de las Myrtaceae e Leptospermaceae argentinas. Lilloa 32: 323-368.

Kawasaki, M.L. 1989. Flora da Serra do Cipó, Minas Gerais: Myrtaceae. Boletim de Botânica da Universidade São Paulo 11: 121-170.

Klein, R.M. 1984. A importância sociológica das mirtáceas nas florestas rio-grandenses. Pp. 367-375. In: Anais do 24 Congresso Nacional De Botânica. Porto Alegre 1990. Sociedade Botânica do Brasil. Porto Alegre.

Landrum, L.R. \& Kawasaki, M.L. 1997. The Genera of Myrtaceae in Brazil: an Illustrated Synoptic Treatment and Identification Keys. Brittonia 49(4): 508-536.

Legrand, C.D. 1968. Las Mirtaceas del Uruguay III. Boletín de Facultad de Agronomía de Montevideo 101: 1-80

Legrand, C.D. \& Klein, R.M. 1972. Mirtáceas. Pp. 553-569. In: P.R. Reitz (ed.). Flora Ilustrada Catarinense. Herbário Barbosa Rodriques, Itajaí. 
Legrand, C.D. \& Klein, R.M. 1977. Mirtáceas. Pp. 570-730. In: P.R. Reitz (ed.). Flora Ilustrada Catarinense. Herbário Barbosa Rodriques, Itajaí.

Legrand, C.D. \& Klein, R.M. 1978. Mirtáceas Pp.731-876. In: P.R. Reitz (ed.). Flora Ilustrada Catarinense. Herbário Barbosa Rodriques, Itajaí.

Leitão Filho, H.F. 1993. Ecologia da Mata Atlântica de Cubatão (São Paulo). Editora da Universidade Estadual de São Paulo, Campinas.

Lorenzi, H. 1998. Árvores Brasileiras: Manual de identificação e cultivo de plantas arbóreas nativas do Brasil. Plantarum, Nova Odessa. v.2.

Maack, R. 1968. Geografia física do Estado do Paraná. J. Olympio, Rio de Janeiro.

Marchiori, J.N.C. \& Sobral, M. 1997. Dendrologia das Angiospermas: Myrtales. Universidade Federal de Santa Maria, Santa Maria.

McVaugh, R. 1968. The genera of American Myrtaceae, a interim report. Taxon 17(8): 354-418.

Mori, S.A.; Boom, B.M.; Carvalho, A.M. \& Santos, T.S. 1983. Ecological Importance of Myrtaceae in an Eastern Brazilian Wet Forest. Biotropica 15: 68-70.

Nakajima, J.N.; Soares-Silva, L.H.; Medri, M.E.; Goldenberg, R. \& Correa, G.T. 1996. Composição florística e fitossociológica do componente arbóreo das florestas ripárias da Bacia do rio Tibagi: 5. Fazenda Monte Alegre, Município de Telêmaco Borba, Paraná. Arquivos de Biologia e Tecnologia 39(4): 933-948.

Paraná. 1987. Secretaria de Estado da Agricultura e do Abastecimento. Atlas do Estado do Paraná. Instituto de Terras, Cartografia e Florestas, Curitiba.

Radford, A.E.; Dickson, W.C.; Massey, J.R. \& Bell, C.R. 1974. Vascular plant systematics. Harper \& Row, New York.

Rodrigues, R.R. \& Nave, A.G. 2000. Heterogeneidade florística das matas ciliares. Pp. 45-71. In: R.R. Rodrigues \& H.F. Leitão Filho (eds.). Matas ciliares: conservação e recuperação. EDUSP, Fapesp. São Paulo.
Romagnolo, M.B. \& Souza, M.C. 2000. Análise florística e estrutural de florestas ripárias do alto rio Paraná, Taquaruçu, MS. Acta Botanica Brasilica 14(2): 163-174.

Rotman, A.D. 1979. Las Especies Argentinas del Género Myrcianthes (Myrtaceae). Darwiniana 22(1-3): 109-123.

Rotman, A.D. 1982. Los Géneros Calycorectes, Hexachlamys, Myrciaria, Paramyrciaria, Plinia y Siphoneugena en la Flora Argentina. Darwiniana 24 (14): 157-185.

Rotman, A.D. 1985. Nota sobre um epiteto especifico en el género Plinia (Myrtaceae). Boletin de la Sociedad Argentina de Botáncia 24(1-2): 195.

Rotman, A.D. 1986. Las Myrtaceae del Noroeste Argentino. Darwiniana 27(1-4): 507-526.

Soares-Silva, L.H. 2000. A Família Myrtaceae - Subtribos: Myrciinae e Eugeniinae na Bacia Hidrográfica do Rio Tibagi, Estado do Paraná, Brasil. Tese de Doutorado. Universidade Estadual de Campinas, Campinas.

Sobral, M. 1991. Sinopsis de las Species Reconocidas del Género Paramyrciaria Kausel (Myrtaceae). Candollea 46: $512-521$.

Sobral, M. 1993. Sinopse de Myrciaria (Myrtaceae). Napaea 9: $13-41$.

Souza, M.C.; Romagnolo, M.B. \& Kita, K. 2004. Riparian vegetation: ecotones and plants comunites. Pp. 330-370. In: A.A. Agostinho; S.M. Thomaz \& N.S. Hahn (eds.). The Upper Parana River Floodplain: Physical Aspects, Ecology and Conservation. Editora Backhuys.

Souza, M.C.; Cislinski, J. \& Romagnolo, M.B. 1997. Levantamento florístico. Pp. 345-370. In: A.E.A.M Vazzoler; A.A. Agostinho \& N.S. Hahn (eds.). A planície de inundação do alto rio Paraná: aspectos físicos, biológicos e socioeconômicos. Editora da Universidade Estadual de Maringá, Maringá.

Stevaux, J.C. 1994. Geomorfologia, sedimentologia e paleoclimatologia do Alto Curso do rio Paraná (Porto Rico, PR). Boletim Paranaense de Geociências 42: 97-112. 